\title{
Jewelry as a Kind of Household Savings of Uzbekistan
}

\author{
Inna Stecenko ${ }^{1, *}$, Anvar Irchaev ${ }^{2}$ \\ ${ }^{1}$ Baltic International Academy, Doctoral Program, Regional Economy and Economics Policy, Latvia \\ ${ }^{2}$ Investment Group Tashkent, Uzbekistan
}

Copyright $\subset 2017$ by authors, all rights reserved. Authors agree that this article remains permanently open access under the terms of the Creative Commons Attribution License 4.0 International License

\begin{abstract}
The goal of the present research is to study the influence of price increase on gold and on the level of household savings of Uzbekistan. The authors put forward the hypothesis - the higher the prices of gold, the more active the households of Uzbekistan invest in jewelry. Thus, the authors supplemented the theory of Gustav Kassel - the growth of the world prices of gold not only influence on the level of exchange rate level, but also on the level of household savings. The carried out analysis, using the econometric methods has shown that the households of RUz invest in jewelry, which are used as savings.
\end{abstract}

Keywords Households, Savings, Jewelry, Uzbekistan

\section{Introduction}

The level of savings of households in the modern economy is important in the economy of the state as a whole, as from the level of savings depends on the sustainable development of both the household itself and the country as a whole. The authors examined the theory of G. Kassel [1] concerning the influence of the world prices of gold and on the level of the currency exchange rate of the national currencies, by assuming that the price increase of gold has influence on the level of household savings as well. However, according to the opinion of the authors, the level of savings of households is not worth considering only from the standpoint of finances, a number of theories has influence on the level of household savings, including the theories of marketing - $(\mathrm{H}$.
Leibenstein [2] theory - luxury consumption, Veblen's [3] theory - conspicuous consumption), and theories of economic sociology (Abolafia [4] Cultural-historical approach).

The methods of research-for carrying out the research, the authors used the econometric methods (correlation and regression analyses). The calculations were made, using EXEL program.

\section{Materials and Methods}

Based on the studies put forward by the author, the hypothesis which is the level of household savings rate affects the price of gold on world markets. So provided by the author Table 1 The structure of consumption of the residents of Uzbekistan, the structure of consumption by major commodity groups, where it is shown that the level of consumption increases on the basis of total income, but household planning specificity is to ensure that the increases and the volume of purchase jewelry, which are traditionally in the country are a form of savings.

During the study 17 years from 1995 to 2012 the volume of consumption of Jewelry has increased almost 10 times! If we compare with these kinds of consumption as televisions that sales in 2012 amounted to 20.7 billion UZS, while the jewelry - 28.7. Of course, jewelry is not related to essential commodities, the population uses these acquisitions as savings.

Table 1. Consumption in the Republic of Uzbekistan during the period from 1995 - 2012, (mln USD) (Compiled by the authors) [5]

\begin{tabular}{|c|c|c|c|c|c|c|}
\hline & 1995 & 2000 & 2005 & 2010 & 2011 & 2012 \\
\hline All goods & 106,7 & 1787,5 & 5577,4 & 21872,8 & 28539 & 36946 \\
\hline Foodstuffs & 68,5 & 1081,4 & 2896,4 & 10583,7 & 14338,5 & 18166,4 \\
\hline Non-food products & 38,2 & 706,1 & 2681,0 & 11289,1 & 14200,5 & 18779,6 \\
\hline Jewelry & $\mathbf{0 , 3}$ & $\mathbf{3 , 2}$ & $\mathbf{8 , 8}$ & $\mathbf{3 1 , 6}$ & $\mathbf{3 3 , 1}$ & $\mathbf{2 8 , 5}$ \\
\hline
\end{tabular}


Table 2. Analysis of fluctuation of currency and gold deposits of the population of the Republic of Uzbekistan during the period from 2005-2015 (Compiled by the authors) [5], [6], [7]

\begin{tabular}{|c|c|c|c|c|c|c|c|c|c|c|c|}
\hline $\begin{array}{c}\text { Indicators/ } \\
\text { Years }\end{array}$ & $\mathbf{2 0 0 5}$ & $\mathbf{2 0 0 6}$ & $\mathbf{2 0 0 7}$ & $\mathbf{2 0 0 8}$ & $\mathbf{2 0 0 9}$ & $\mathbf{2 0 1 0}$ & $\mathbf{2 0 1 1}$ & $\mathbf{2 0 1 2}$ & $\mathbf{2 0 1 3}$ & $\mathbf{2 0 1 4}$ & $\mathbf{2 0 1 5}$ \\
\hline $\begin{array}{c}\text { Course UZS to } \\
\text { the US dollar }\end{array}$ & 1174,02 & 1240,00 & 1290,00 & 1393,00 & 1511,4 & 1640,0 & 1640,0 & 1795.05 & 1984,0 & 2202,20 & 2422 \\
\hline $\begin{array}{c}\text { Price for 1 gram } \\
\text { of gold }\end{array}$ & 472,35 & 535,47 & 654,69 & 821,8 & 1062,32 & 1383,03 & 1629,81 & 1629,81 & 1264 & 2146 & 2502 \\
\hline $\begin{array}{c}\text { Population } \\
\text { deposits billion. } \\
\text { Sum }\end{array}$ & 450 & 533,7 & 3829,2 & 5771,6 & 29000 & 44000 & 43000 & 626000 & 698000 & 19,8 & 28,5 \\
\hline Inflation, \% & 7,8 & 6,8 & 6,8 & 7,8 & 7,4 & 5,2 & 4,6 & 4.9 & 4,37 & 4,5 & 5,6 \\
\hline
\end{tabular}

Given the reduction theory of Gustav Cassel, which showed that the level of purchasing ability of the currency affects the price of gold on international markets, the author proposes to consider the change in the exchange rate (Uzbek sum), the world price of gold and the amount of household savings.

Next to valuation according to the level of household savings spend calculation of correlation between the level of inflation and deposits, deposits and the level of the price of gold, a change of course sum to the dollar and the value of an ounce on the stock exchange.

In this case, we can use a correlation analysis.

The goal of the correlation analysis is to determine the degree of dependence between factorial and resultant signs.

The value of linear connection of two signs characterizes the coefficient of linear correlation which is denoted $r$.

The value of correlation coefficient can be calculated by the following formula (Pearson correlation coefficient [8]):

$$
r=\frac{\sum_{i=1}^{n}\left(x_{i}-\bar{x}\right)\left(y_{i}-\bar{y}\right)}{\sqrt{\sum_{i=1}^{n}\left(x_{i}-\bar{x}\right)^{2}} \sqrt{\sum_{i=1}^{n}\left(y_{i}-\bar{y}\right)^{2}}}=\frac{n \sum_{i=1}^{n} x_{i} y_{i}-\left(\sum_{i=1}^{n} x_{i}\right)\left(\sum_{i=1}^{n} y_{i}\right)}{\sqrt{n \sum_{i=1}^{n} x_{i}^{2}-\left(\sum_{i=1}^{n} x_{i}\right)^{2}} \sqrt{n} \sum_{i=1}^{n} y_{i}^{2}-\left(\sum_{i=1}^{n} y_{i}\right)^{2}}
$$

Where, $\bar{x}$ and $\bar{y}$ mean values of $X$ and $Y$ :

$$
\bar{x}=\frac{1}{n} \sum_{i=1}^{n} x_{i}, \bar{y}=\frac{1}{n} \sum_{i=1}^{n} y_{i} .
$$

$n$ - sample number;

$i$ - number of observation.

The correlation coefficient can be calculated in MS Excel, using CORREL functions.

The correlation matrix of two signs $\mathrm{X}$ and $\mathrm{Y}$ is called the matrix of the form:

$$
\left(\begin{array}{ll}
r_{x x} & r_{x y} \\
r_{y x} & r_{y y}
\end{array}\right)
$$

The correlation relationship between the values of one and the same attribute, for example, called autocorrelation, its value always equals to $1: r_{x x}=1$.

Let's consider the regression models with one equation. In such models the dependent (explained) variable $y$ is represented as a function

$f(x, \beta)=\left(x_{1}, x_{2}, \ldots, x_{k} ; \beta_{1}, \beta_{2}, \ldots, \beta_{n}\right)$, where $x_{1}$, $x_{2}, \ldots, x_{k}$ - independent (explained) variables, but $\beta_{1}$, $\beta_{2}, \ldots, \beta_{n}$ - parameters.

Depending on the type of function $f(x, \beta)$ the models are divided into linear

$f(x, \beta)=\beta_{0}+\beta_{1} x_{1}+\beta_{2} x_{2}+\ldots+\beta_{n} x_{n}$ and nonlinear.

The field of application of such models, even linear is much wider than the time - series models. The problems of estimation theory, verification, selection of relevant parameters and the other are devoted to a huge amount of literature.

This topic is pivotal in econometrics.

If the points on the correlation diagram to connect with the broken line, then, the empirical regression line is obtained (i.e., derived empirically).

Smoothing the empirical regression line by a straight line or a curve, obtain the theoretical regression line. Depending on the nature of obtained line distinguish linear and nonlinear regressions. In the case of a linear regression the empirical regression line is smoothed by a straight line.

It is commonly known that the equation of straight line takes the form [8]:

$$
y=k x+b
$$

Where $k=\operatorname{tg} \alpha-$ inclination of line to the axis $O x$;

$b$ - point of intersection of line of regression and axis $O y$;

By the analogue with this equation, in the cases of linear regression the dependence between the factorial sign $X$ and effective sign $Y$ decribes the following model:

$$
y_{i}=\beta_{0}+\beta_{1} x_{i}+\varepsilon_{i}
$$

Where $\beta_{0}$ and $\beta_{1}$ - is the unknown coefficients of the regression equation;

$\varepsilon$ - regression residue;

$i$ - the number of observation, $i=1,2, \ldots, n$.

To find an exact expression for this equation is not possible as it is impossible to take into the consideration the influence of all factors, affecting the effective sign. 
Therefore it is considered that the term $\varepsilon$ is called the regression residue (or just residue) reflects the combined impact of all other unaccounted factors on the value $y$.

The linear function of regression is found in the data sample, is written in the following way:

$$
\hat{y}_{i}=\hat{\beta}_{0}+\hat{\beta}_{1} x_{i}, \quad i=1,2, \ldots, n
$$

Or

$$
y_{i}=\hat{\beta}_{0}+\hat{\beta}_{1} x_{i}+\hat{\varepsilon}_{i}, i=1,2, \ldots, n
$$

Where: $\hat{y}_{i}$ - evaluation sign of $Y$, obtained in the data sample;

$\hat{\beta}_{0}$ and $\hat{\beta}_{1}$ - the estimates of coefficients of regression equation of $\beta_{0}$ and $\beta_{1}$;

$\hat{\varepsilon}_{i}=y_{i}-\hat{y}_{i}$ - estimation error of $\varepsilon_{i}$;

$n$ - sample size.

The actual and evaluation data of regression model are represented in Fig 2. The points on the graph represent the actual data; a straight line represents their approximation, i.e., is described by our estimation equation (5).

Thus, the following which we will use in our research is the least square method [8].

At the heart of the least square method (LSM) lies in such values of coefficient $\beta_{0}$ and $\beta_{1}$, wherein error UZS of squares would be the least. Found by the means of LSM the regression line $\hat{y}_{i}=\hat{\beta}_{0}+\hat{\beta}_{1} x_{i}$ represents a straight line that minimizes the UZS of squares i.e.,

$$
\sum_{i} \hat{\varepsilon}_{i}^{2}=\sum_{i}\left(y_{i}-\hat{y}_{i}\right)^{2}=\sum_{i}\left(y_{i}-\hat{\beta}_{0}-\hat{\beta}_{1} x_{i}\right)^{2} \rightarrow \min
$$

Let's denote this function as SS. In order to find the regression line, it is necessary to solve the system of equations, regarding the unknown parameters $\hat{\beta}_{0}$ and $\hat{\beta}_{1}$.

The necessary conditions of existence of extremum ( $\mathrm{min})$ according to $\hat{\beta}_{0}$ and $\hat{\beta}_{1}$ function $S S\left(\hat{\beta}_{0}, \hat{\beta}_{1}\right)$ - the equality 0 of partial derivatives of this function: $\frac{\partial S S}{\partial \hat{\beta}_{0}}=0$ and $\frac{\partial S S}{\partial \hat{\beta}_{1}}=0$.

We get the following system of equations:

$$
\left\{\begin{array}{l}
\frac{\partial S S}{\partial \hat{\beta}_{0}}=-2 \sum_{i}\left(y_{i}-\hat{\beta}_{0}-\hat{\beta}_{1} x_{i}\right)=0, \\
\frac{\partial S S}{\partial \hat{\beta}_{1}}=-2 \sum_{i} x_{i}\left(y_{i}-\hat{\beta}_{0}-\hat{\beta}_{1} x_{i}\right)=0 .
\end{array}\right.
$$

This system can be rewritten in the following way: In the result of solution of this system of equations we obtain the values of regression coefficients $\hat{\beta}_{0}$ and $\hat{\beta}_{1}$ :

$$
\begin{gathered}
\hat{\beta}_{1}=\frac{\sum_{i=1}^{n}\left(y_{i}-\bar{y}\right)\left(x_{i}-\bar{x}\right)}{\sum_{i=1}^{n}\left(x_{i}-\bar{x}\right)^{2}}=\frac{n \sum_{i=1}^{n} x_{i} y_{i}-\sum_{i=1}^{n} x_{i} \sum_{i=1}^{n} y_{i}}{n \sum_{i=1}^{n} x_{i}^{2}-\left(\sum_{i=1}^{n} x_{i}\right)^{2}}=\frac{\overline{x y}-\bar{x} \bar{y}}{\overline{x^{2}}-\bar{x}^{2}} \\
\hat{\beta}_{0}=\bar{y}-\hat{\beta}_{1} \bar{x}=\frac{\sum_{i=1}^{n} y_{i} \sum_{i=1}^{n} x_{i}^{2}-\sum_{i=1}^{n} x_{i} \sum_{i=1}^{n} x_{i} y_{i}}{n \sum_{i=1}^{n} x_{i}^{2}-\left(\sum_{i=1}^{n} x_{i}\right)^{2}}
\end{gathered}
$$

The indicator of slope of the regression line $\hat{\beta}_{0}$ it can be calculated in MS Excel, using the functions of INTERCEPT. The function syntax INTERCEPT:

INTERCEPT(Known_y's;Known_x's),

Where: Known_y's - data area of effective (dependent) sign,

Known_x's - data area of effective (independent) sign.

The angle of deflection of regression line $\hat{\beta}_{1}$ can be calculated in MS Excel, using the function SLOPE, arguments of which coincide with the arguments of INTERCEPT function.

Function syntax SLOPE:

\section{SLOPE(Known y's;Known x's).}

In the result, we obtain the correlation diagram on which the drawn line of regression and represented the equation of linear regression together with the coefficient of determination.

The systems of simultaneous equations. The data of system may consist of identities and regression equations, each of which may except the explanatory variables also include the explanatory variables from the other system of equations. Thus, we have here a set of explanatory variables, related through the system of equations.

So spend a correlation analysis based inflation rate and deposits of the population, the data represented in Table 3. 
Table 3. Analysis of the dependence rate of inflation and population's deposits in the period from 2005 to 2015 (calculated by the authors)

\begin{tabular}{|c|c|c|}
\hline Year & Inflation, $\%$ & Deposits population, bln. UZS \\
\hline 2005 & 7,8 & 450 \\
\hline 2006 & 6,6 & 533 \\
\hline 2007 & 6,8 & 3929 \\
\hline 2008 & 7,8 & 6771,6 \\
\hline 2009 & 7,4 & 29000 \\
\hline 2010 & 7,3 & 44000 \\
\hline 2011 & 7,6 & 43000 \\
\hline 2012 & 7 & 626000 \\
\hline 2013 & 6,8 & 698000 \\
\hline 2014 & 4,5 & 1980000 \\
\hline 2015 & 5,6 & 2850000 \\
\hline \multicolumn{3}{|c|}{ Correlation $=-0,43987$} \\
\hline
\end{tabular}

As you can see from the above calculations for the period from 2005 to 2015 the relationship between inflation and no deposits of the population: Although the state to attract deposits set a high interest rate, so it was the level of $30-35 \%$ in 2009 year, however, the correlation between performance ratio no indicator is negative: $-0,43987$

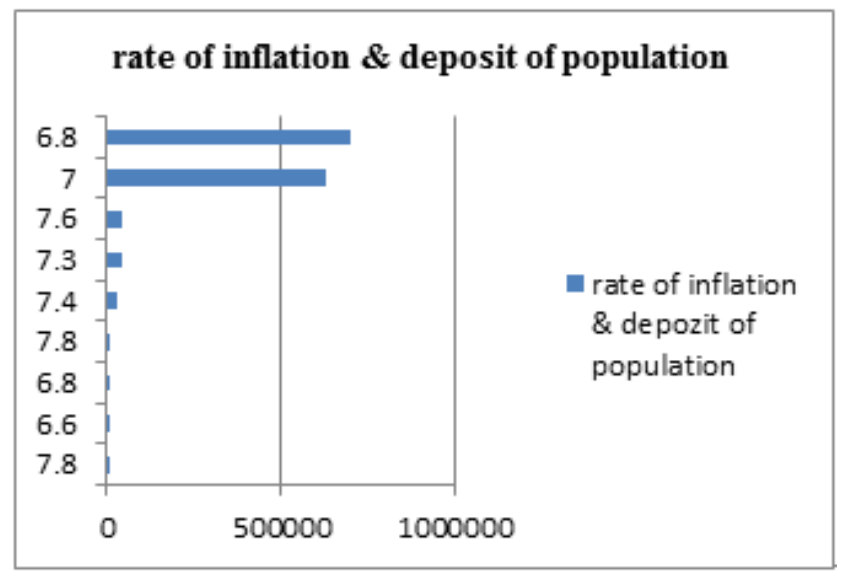

Figure 1. The dependence of the amount of deposits of the population on the level of inflation in the Republic of Uzbekistan

From the presented graph shows that not only there is no correlation between the level of inflation and the deposits of the population, but there is a nonlinear relationship, the higher the inflation the less people trust the bank deposits.

Further, in our opinion, it is necessary to consider the rate depending on the price of gold in the world with the fluctuations of the national currency (Table 4).
Table 4. Dependence fluctuations Uzbek sum of world prices for gold (calculated authors)

\begin{tabular}{|c|c|c|}
\hline Years & preis of gold & UZS/USD \\
\hline 2005 & 472,35 & 1174,02 \\
\hline 2006 & 535,47 & 1240 \\
\hline 2007 & 654,69 & 1290 \\
\hline 2008 & 821,8 & 1393 \\
\hline 2009 & 1062,32 & 1511,4 \\
\hline 2010 & 1383,03 & 1640 \\
\hline 2011 & 1629,81 & 1795,05 \\
\hline 2012 & 1668,89 & 1984 \\
\hline 2013 & 2146 & 2202 \\
\hline 2014 & 2146 & 2202,20 \\
\hline 2015 & 2502 & 2202,20 \\
\hline & Correlation $=0,98892$ \\
\hline
\end{tabular}

So, how the calculations between the level of prices on the world markets and the level of fluctuations in the UZS, and the US dollar there is a high level of dependence - 0.98892 , which indicates the high dependency fluctuations in gold prices and currency fluctuations (UZS).

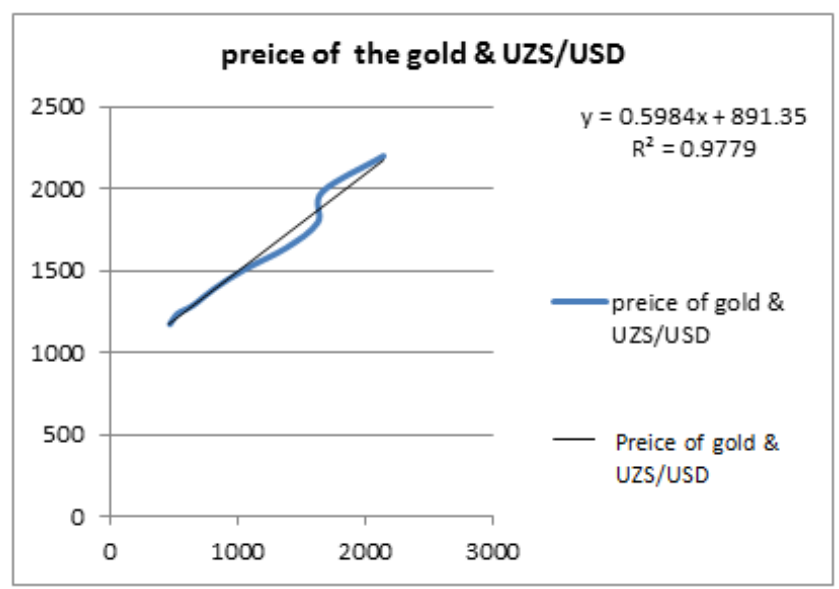

Figure 2. Dependence fluctuations Uzbek sum of world prices for gold. (Author's calculations)

The authors calculated regression equation and the coefficient of determination, $\mathrm{R}^{2}=0,98$ indicates a high dependence between these factors.

Next, to confirm the hypothesis - depending on the level of household savings on the level of world prices for gold, we calculate the correlation of these indicators, the table 5 . 
Table 5. The dependence on the gold price level and the amount of deposits of the population of the Republic of Uzbekistan in the period from 2005 to 2015 (Calculated by the authors)

\begin{tabular}{|c|c|c|}
\hline Year & Price XTR gold, USD & $\begin{array}{c}\text { The sum of deposits of the } \\
\text { population, Billions. UZS }\end{array}$ \\
\hline 2005 & 472,35 & 450 \\
\hline 2006 & 535,47 & 533 \\
\hline 2007 & 654,69 & 3929 \\
\hline 2008 & 821,8 & 6771,6 \\
\hline 2009 & 1062,32 & 29000 \\
\hline 2010 & 1383,03 & 44000 \\
\hline 2011 & 1629,81 & 43000 \\
\hline 2012 & 1668,89 & 626000 \\
\hline 2013 & 1264 & 698000 \\
\hline 2014 & 2146 & 6708902 \\
\hline 2015 & 2502 & 9656696 \\
\hline \multicolumn{2}{|c|}{ Correlation $=\mathbf{0 , 8 7 9 6}$} \\
\hline
\end{tabular}

Conducted by the author calculations indicate a strong enough connection between the price of gold on world markets and the level of deposits of the population. At the same time the level of population's deposits, inflation has no effect. Next, we calculated the level of correlation between the amount of deposits and the rate of the UZS and US dollar.

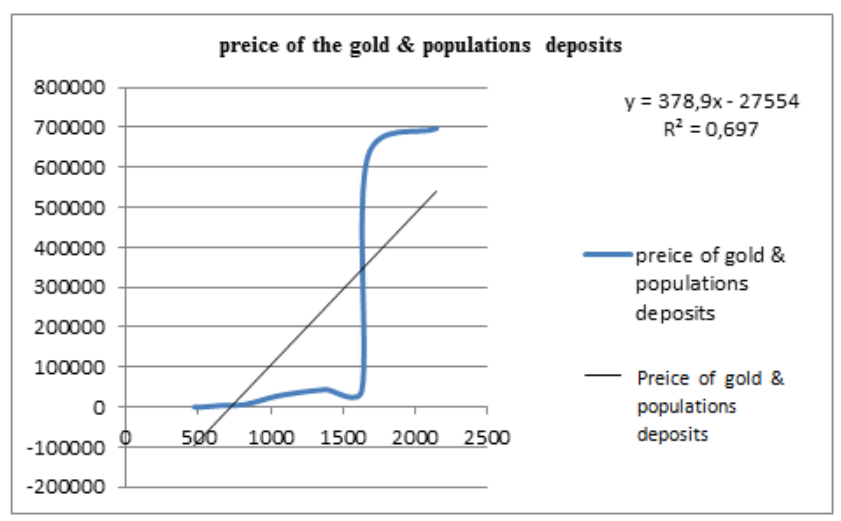

Figure 3. Dependence of world prices for gold and the amount of deposits of the population of Uzbekistan (calculated by the authors).

Thus, calculations show a correlation coefficient of 0.8 , which means that the link between indicators. $\mathrm{R}^{2}$ determination coefficient is also equal to 0.6 confirms the hypothesis - deposits of the population depends on the fluctuations in the price of gold on world markets.

As shown by the calculations in the period from 2005 to 2015, the high level of dependence (correlation 0.87) between the amount of retail deposits and currency fluctuations. This means that the devaluation of the UZS leads to an increase in household deposits.
Table 6. The dependence of the exchange rate of Uzbek sum and the sum of deposits of the population of the Republic of Uzbekistan in the period from 2005 to 2015 (Calculated by the authors)

\begin{tabular}{|c|c|c|}
\hline & UZS/USD & $\begin{array}{c}\text { sum of deposits of the } \\
\text { population, billion UZS }\end{array}$ \\
\hline 2005 & 1174,02 & 450 \\
\hline 2006 & 1240 & 533 \\
\hline 2007 & 1290 & 3929 \\
\hline 2008 & 1393 & 6771,6 \\
\hline 2009 & 1511,4 & 29000 \\
\hline 2010 & 1640 & 44000 \\
\hline 2011 & 1795,05 & 43000 \\
\hline 2012 & 1984 & 626000 \\
\hline 2013 & 2202 & 698000 \\
\hline 2014 & 2146 & 6708902 \\
\hline 2015 & 2502 & 9656696 \\
\hline \multicolumn{2}{|c|}{ Correlation: 0,8677} \\
\hline
\end{tabular}

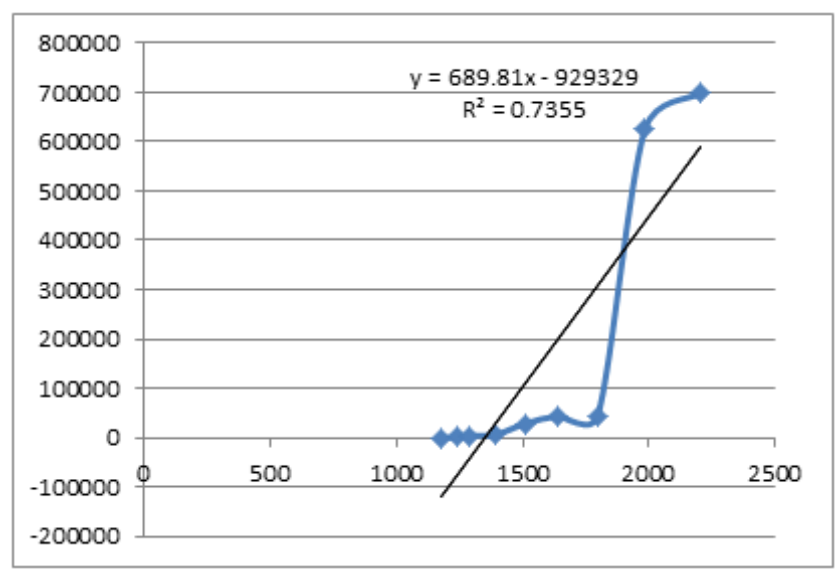

Figure 4. Dependence of Uzbekistan household deposits by currency fluctuations (calculated by the authors)

From these calculations it can be concluded according to the cost of the Uzbek sum of total household deposits. The coefficient of determination $\mathrm{R}^{2}=0,74$, and shows a high level of dependence between the coefficients.

However, our main goal is to confirm the hypothesis put forward by the author on the relationship between the level of savings and the price of gold on the world market level. The extended position of the impact on the level of household savings is not only economic theory but also cultural characteristics (Theory of Lebenstein, Veblen) show that a high level of household savings makes up and jewelry. National traditions give Gold Jewelry to the important events of the population, allowed the author to carry out calculations on the impact on the gold price level on world markets and the purchase of gold jewelry. 
Table 7. The dependence of the world price of gold and the amount of acquired jewels of the Republic of Uzbekistan in the period from 2005 to 2012 (Calculated by the authors)

\begin{tabular}{|c|c|c|}
\hline Year & preis of gold, USD & Jewelery bln.UZS \\
\hline 2005 & 472,35 & 8,8 \\
\hline 2010 & 1383,03 & 31,6 \\
\hline 2011 & 1629,81 & 33,1 \\
\hline 2012 & 1668,89 & 28,5 \\
\hline \multicolumn{3}{|c|}{ Correlation $=0,986339$} \\
\hline
\end{tabular}

Thus, our calculations show that the increase in gold prices and the appreciation of jewelry do not reduce the demand for gold and increased the amount of products purchased. The correlation coefficient is nearly 1, i.e., 0.99! This proves that the population uses jewelry as savings element.

The proof is the fact that the increasing population of the country in terms of national currency devaluation and the increase in world gold prices continue to invest money in jewelry.

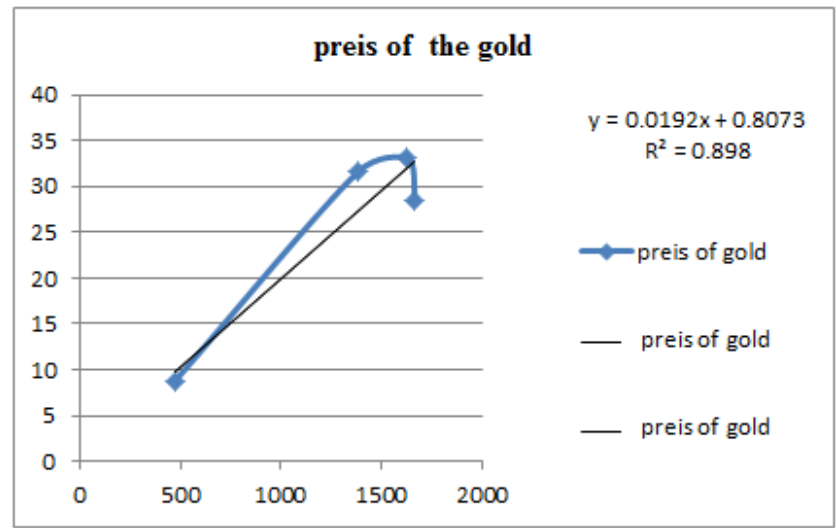

Figure 5. Dependence of world gold prices and consumer demand for jewelry (gold)

As you can see from the graph presented - the higher the price of gold on world markets, the higher the demand of the population of Uzbekistan on jewelry. Graph 4 shows a linear relationship between the two measures. This is confirmed by the coefficient of determination $\mathrm{R}^{2}=0,9$.

Table 8. The dependence of the population growth in the Republic of Uzbekistan and the amount purchased jewelry in the period from 2005 to 2012. (Calculated by the authors)

\begin{tabular}{|c|c|c|}
\hline Year & jewelry, bln. UZS & Popul, bln. human \\
\hline 2005 & 8,8 & 26021,3 \\
\hline 2010 & 31,6 & 28001,4 \\
\hline 2011 & 33,1 & 29123,4 \\
\hline 2012 & 28,5 & 29555,4 \\
\hline \multicolumn{3}{|c}{ Correlation $=0,864756$} \\
\hline
\end{tabular}

Thus, the growing population of the country continues to invest heavily in jewelry, thus forming savings at the household level. The correlation coefficient of 0.86 indicates a high level of dependence of these parameters. When planning the financial policy of the state, the implementation of the business development program should take into account the population data resources.

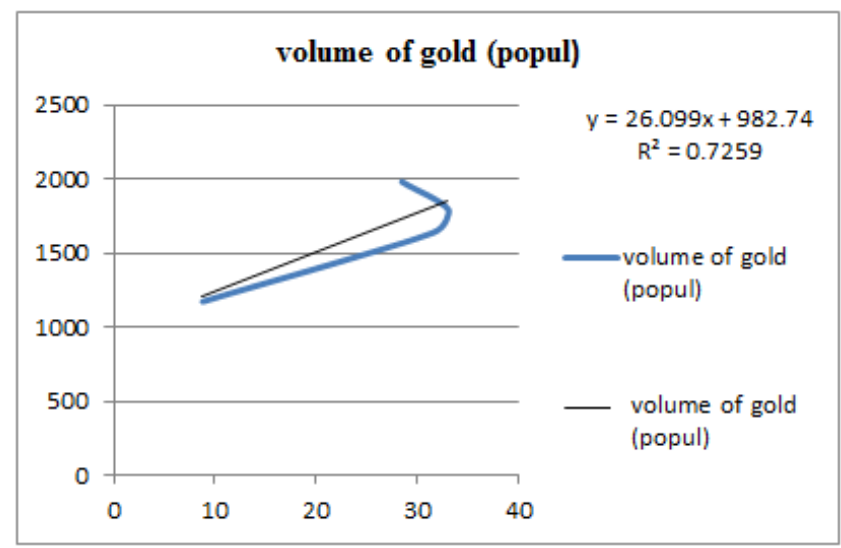

Figure 6. The relationship of population and number of acquired jewels (calculated by the authors)

So, our calculations show that the population of Uzbekistan does not reduce this item of expenditure as purchasing jewelry. Chart 5 shows a linear relationship, and confirms the theory of Veblen and Lebenstein. The calculated coefficient of determination $\mathrm{R}^{2}=0,73$ also indicates a high level of dependence between these indicators.

So, by the authors of the study, have the following conclusions:

\section{Conclusions}

1. Using the techniques of correlation, regression analysis, the author put forward a hypothesis about the dependence of the level of savings in the Republic of Uzbekistan on world gold prices was confirmed. The study found that the people of Uzbekistan a significant part of the savings to invest in jewelry, which confirms the hypothesis of the author, of the influence of cultural characteristics of the level of household savings. The economic policy planning conditions it is necessary to use this important resource of the household savings.

2. Research on the basis of econometric methods showed that inflation has an adverse effect on the level of Uzbekistan's household savings - higher inflation in the country, the less investments, but investment levels in jewelry increases.

\section{REFERENCES}

[1] Karl Gustav Cassel, Das Geldproblem der Welt. München, 1921 
[2] Leibenstein H. Property Rights and X-Efficiency: Comment//American Economic Review, 83, 1983 pp.831-842

[3] Veblen, Thorstein. The Theory of the Leisure Class: An Economic Study of Institutions. Penguin twentieth-century classics. New York: Penguin Books (1994) [1899].p. 167

[4] Mitchel Y. Abolafia Making Markets Opportunism and Restraint on Wall Street. Harvard University Press, 2001, p. 240

[5] O’zbekiston Respublikasi Davlatstatistika, Online available from http://stat.uz/

[6] Banks Association of Republic of Uzbekistan, Online available from http://bank.uz/publish/doc/text116489_ustoychivost_bankovs koy_sistemy_-_zalog_dalneyshey_modernizacii_ekonomiki 1.06.2016
[7] Report of World Bank (2006-2014), Online available from http://www.worldbank.org/

[8] William H. Greene Econometric Analysis, New York University, 2010 p. 66-86, p.257-269

[9] D. Kadochnikov, International coordination of financial and economic policy: scientific heritage of Gustav Cassel, Economics Questions, No. 1, 2012, p.51-64

[10] Tibor Paul Hanappi, Sandra Müllbacher (2016) Tax incentives and family labor supply in Austria Review of Economics of the Household, Volume 14, Issue 4, December 2016, p. 961-987

[11] Carbonnier, Clément (2015) The Political Economy of Household Services in Europe, Palgrave Macmillan, UK p. 288 